\title{
Prognostic impact of malnutrition on cardiovascular events in coronary artery disease patients with myocardial damage
}

Ryo Arikawa, Daisuke Kanda*, Yoshiyuki Ikeda, Akihiro Tokushige, Takeshi Sonoda, Kazuhiro Anzaki and Mitsuru Ohishi

\begin{abstract}
Background: Stable coronary artery disease (CAD) patients with myocardial damage have a poor prognosis compared to those without myocardial damage. Recently, malnutrition has been reported to affect the prognosis of cardiovascular diseases. However, the effects of malnutrition on prognosis of CAD patients with myocardial damage remains uncertain. We investigated the effects of malnutrition on prognosis of CAD patients with myocardial damage who received percutaneous coronary intervention $(\mathrm{PCl})$.

Methods: Subjects comprised 241 stable CAD patients with myocardial damage due to myocardial ischemia or infraction. Patients underwent successful revascularization for the culprit lesion by PCl using second-generation drugeluting stents and intravascular ultrasound. The geriatric nutritional risk index (GNRI), which is widely used as a simple method for screening nutritional status using body mass index and serum albumin, was used to assess nutritional status. Associations between major cardiovascular and cerebrovascular events (MACCE) and patient characteristics were assessed.

Results: Mean GNRI was $100 \pm 13$, and there were 55 malnourished patients $(23 \%$; GNRI < 92$)$ and 186 non-malnourished patients (77\%). MACCE occurred within 3 years after PCI in 42 cases (17\%), including 34 deaths (14\%), and the malnourished group showed a higher rate of MACCE (38\%) compared with the non-malnourished group (11\%, $p<0.001)$. Univariate Cox proportional hazards analyses showed that MACCE was associated with age [hazard ratio $(\mathrm{HR}), 1.04 ; 95 \%$ confidence interval $(\mathrm{Cl}), 1.04-1.07 ; p=0.004]$, prior heart failure (HR 2.35; 95\% Cl 1.10-5.01; $p=0.027)$, high-sensitivity C-reactive protein ( $\mathrm{HR} \mathrm{1.08;95 \%} \mathrm{Cl} \mathrm{1.03-1.11;} p<0.001$ ), hemodialysis (HR 2.63; 95\% Cl 1.51-4.58; $p<0.001$ ) and malnutrition (HR 3.69; 95\% Cl 2.11-6.42; $p<0.001$ ). Multivariate Cox proportional hazards analysis revealed hemodialysis ( $\mathrm{HR} 2.17 ; 95 \% \mathrm{Cl} 1.19-3.93 ; p=0.011$ ) and malnutrition (HR 2.30; 95\% Cl 1.13-4.67; $p=0.020$ ) as significantly associated with MACCE. Furthermore, Cox proportional hazards models using malnutrition and hemodialysis revealed that patients with malnutrition and hemodialysis were at greater risk of MACCE after PCI than patients with neither malnutrition nor hemodialysis (HR 6.91; 95\% Cl 3.29-14.54; $p<0.001$ ).
\end{abstract}

Conclusions: In CAD patients with myocardial damage, malnutrition $(G N R I<92)$ represents an independent risk factor for MACCE. Assessment of nutritional status may help stratify the risk of cardiovascular events and encourage improvements in nutritional status.

\footnotetext{
*Correspondence: kanchan@m3.kufm.kagoshima-u.ac.jp

Department of Cardiovascular Medicine and Hypertension, Graduate

School of Medical and Dental Sciences, Kagoshima University, 8-35-1

Sakuragaoka, Kagoshima City, Kagoshima 890-8520, Japan
}

(c) The Author(s) 2021. Open Access This article is licensed under a Creative Commons Attribution 4.0 International License, which permits use, sharing, adaptation, distribution and reproduction in any medium or format, as long as you give appropriate credit to the original author(s) and the source, provide a link to the Creative Commons licence, and indicate if changes were made. The images or other third party material in this article are included in the article's Creative Commons licence, unless indicated otherwise in a credit line to the material. If material is not included in the article's Creative Commons licence and your intended use is not permitted by statutory regulation or exceeds the permitted use, you will need to obtain permission directly from the copyright holder. To view a copy of this licence, visit http://creativecommons.org/licenses/by/4.0/. The Creative Commons Public Domain Dedication waiver (http://creativeco mmons.org/publicdomain/zero/1.0/) applies to the data made available in this article, unless otherwise stated in a credit line to the data. 
Keywords: Malnutrition, Coronary artery disease, Myocardial damage, Percutaneous coronary intervention, Hemodialysis

\section{Background}

Cardiovascular disease is the leading cause of mortality and disability around the world [1]. Despite recent clinical advances in percutaneous coronary intervention (PCI) and medical therapy [2], coronary artery disease (CAD) remains a major issue worldwide [1]. Assessment of risk stratification for mortality and cardiovascular events in patients with CAD is therefore crucial when making medical decisions $[3,4]$.

Malnutrition is common among hospitalized patients and has been reported to be associated with worsened prognosis among patients with chronic diseases such as cancer [5] and renal failure [6]. Various tools are available for the evaluation of nutritional status, and the geriatric nutritional risk index (GNRI) is widely used as a simple method for screening nutritional status using body mass index (BMI) and serum albumin [7]. The GNRI was a tool created to study and predict nutrition-related complications in elderly patients and was initially proposed for sub-acute care setting [7]. Recent studies have demonstrated that GNRI is associated with worsened prognosis in heart failure patients [8], and with mortality in patients with chronic life-threatening ischemia [9]. GNRI could thus be important for risk stratification even in patients with cardiovascular disease.

Stable CAD patients with myocardial damage display poor prognosis compared to those without myocardial damage [10]. However, the impact of malnutrition on the prognosis of CAD patients with myocardial damage remains unclear. The present study aimed to evaluate the prognostic value of nutritional status using GNRI in stable CAD patients with myocardial damage.

\section{Methods \\ Study population}

We evaluated a retrospective cohort in a single center, investigating 241 consecutive patients with stable CAD and myocardial damage admitted to Kagoshima University Hospital between January 2015 and August 2018 for PCI. All patients underwent coronary angiography and successful revascularization for the culprit lesion by PCI using a standard technique with second-generation drugeluting stents and intravascular ultrasound. All patients were administered dual antiplatelet therapy (aspirin and thienopyridine: prasugrel or clopidogrel) before the procedure. Patients were followed up at our hospital or by their physician. In this study, patients with acute coronary syndrome were excluded. Patients who could not be tracked after discharge were also excluded. Acute coronary syndrome was defined as either acute myocardial infarction (ST-segment elevation myocardial infarction or non-ST segment elevation myocardial infarction) or unstable angina pectoris.

\section{Measurements and assessments of GNRI}

Laboratory values were obtained at the time of admission before PCI. Levels of serum albumin, cholinesterase, high-sensitivity C-reactive protein (hs-CRP), high-density lipoprotein cholesterol (HDL-C), lowdensity lipoprotein cholesterol (LDL-C), total cholesterol ( $\mathrm{T}-\mathrm{CHO})$, triglycerides, creatinine, uric acid, and fasting plasma glucose were measured, and estimated glomerular filtration rate (eGFR) was calculated using the Modification of Diet in Renal Disease equation with coefficients modified for Japanese patients as follows: eGFR $\left(\mathrm{ml} / \mathrm{min} / 1.73 \mathrm{~m}^{2}\right)=194 \times$ serum creatinine $(\mathrm{mg} /$ $\mathrm{dL})^{-1.094} \times$ age $(\text { years })^{-0.287}(\times 0.739$ for female subjects $)$ [11]. Blood samples were drawn after $12 \mathrm{~h}$ of fasting and serum levels of albumin were measured by modified bromocresol purple method (KAINOS, Tokyo, Japan).

This study assessed nutritional status using the GNRI, calculated using the following equation: GNRI $=14.89 \times$ serum albumin level in g/ $\mathrm{dL}+41.7 \times$ (body weight in kilograms/ideal body weight) [7]. Body weight/ideal body weight was set to 1 when the bodyweight of the patient exceeded the ideal bodyweight. Ideal bodyweight was calculated using a BMI of $22 \mathrm{~kg} /$ $\mathrm{m}^{2}$. BMI was calculated as bodyweight in kilograms divided by height in meters squared. Japan Society for the Study of Obesity suggests that ideal BMI is $22 \mathrm{~kg} / \mathrm{m}^{2}$ and obesity is a BMI greater than or equal to 25 [12]. Therefore, we used $22 \mathrm{~kg} / \mathrm{m}^{2}$ as ideal BMI.

\section{Definitions}

In all patients, echocardiography was performed on admission before PCI, and left ventricular asynergy due to myocardial ischemia or infarction was defined as myocardial damage in this study. Conventional transthoracic echocardiographic examinations were performed using a commercially available ultrasound transducer and equipment. Echocardiography measurements were performed according to the guidelines of the American Society of Echocardiography [13]. We estimated left ventricular ejection fraction (LVEF) using the biplane Simpson method. Myocardial ischemia was evaluated by fractional flow reserve or myocardial perfusion 
single-photon emission computed tomography. Patients with GNRI $<92$ at baseline were defined as the malnourished group based on previously published thresholds [7]. Hypertension was defined based on the following criteria: systolic blood pressure $\geq 140 \mathrm{mmHg}$, diastolic blood pressure $\geq 90 \mathrm{mmHg}$, or the use of antihypertensive medication. Diabetes mellitus was defined based on the following criteria: use of antihyperglycemic medication, fasting plasma glucose concentration $>126 \mathrm{mg} /$ $\mathrm{dL}$, or glycosylated hemoglobin concentration $\geq 6.5 \%$ (in accordance with the National Glycohemoglobin Standardization Program) [14]. Dyslipidemia was defined as low-density lipoprotein cholesterol $\geq 140 \mathrm{mg} / \mathrm{dL}$, triglycerides $\geq 150 \mathrm{mg} / \mathrm{dL}$, high-density lipoprotein cholesterol $<40 \mathrm{mg} / \mathrm{dL}$, or use of antidyslipidemic medication. Current smokers were defined as those who were actively smoking at the time of admission.

\section{Clinical outcomes}

Clinical outcomes were retrospectively collected during follow-up. All-cause death was defined as any death after PCI. Major cardiovascular and cerebrovascular events (MACCE) constituted a composite endpoint including all-cause death, non-fatal myocardial infarction, and ischemic stroke.

Patients were divided into a malnourished group $(\mathrm{GNRI}<92)$ and a non-malnourished group, then MACCE after PCI was compared between groups.

\section{Statistical analysis}

Quantitative data are presented as mean \pm standard deviation or median and interquartile range (IQR). Fisher's exact test was used to compare the incidences of categorical variables, expressed as frequency and percentage. Continuous variables were compared between malnourished and non-malnourished groups using Student's t-test (for values showing a normal distribution) or the Wilcoxon rank-sum test (for values showing a nonnormal distribution). Cumulative survival rate and rate of MACCE were estimated using a Kaplan-Meier curve evaluated by log-rank testing. Cox proportional hazards regression analysis was used to analyze factors associated with MACCE, reporting hazard ratios (HRs) and 95\% confidence intervals (CIs). Variables showing values of $p<0.05$ on univariate analysis were entered into multivariate analysis. Furthermore, Cox proportional hazards regression model was performed to assess HRs for MACCE, and results were expressed by forest plots. In addition, we conducted a test for interaction of malnutrition and hemodialysis. Values of $p<0.05$ were considered to indicate statistical significance. Statistical analyses were performed using SAS software (JMP version 14.0).

\section{Results}

Baseline characteristics

The baseline clinical characteristics of patients are shown in Table 1. Mean age was $70 \pm 11$ years, and 163 patients (68\%) were male. Mean GNRI was $100 \pm 13$, and participants comprised 55 malnourished patients (23\%; GNRI $<92$ ) and 186 non-malnourished patients $(77 \%)$. Malnourished patients were older ( $77 \pm 9$ years) than those without malnutrition $(67 \pm 11$ years, $p<0.001)$, and sex (male) had a significant difference between malnourished and non-malnourished patients $(p=0.009)$. The malnourished group showed a lower frequency of dyslipidemia and a higher frequency of hemodialysis compared with the non-malnourished group $(p<0.001$ and $p=0.009$, respectively). Median concentration of hs-CRP was higher in the malnourished group $(3.1 \mathrm{mg} / \mathrm{dL}$; IQR, $0.36-8.26 \mathrm{mg} / \mathrm{dL}$ ) than in the non-malnourished group $(0.19 \mathrm{mg} / \mathrm{dL} ; \mathrm{IQR}, 0.08-0.58 \mathrm{mg} / \mathrm{dL} ; p<0.001)$. Levels of $\mathrm{T}-\mathrm{CHO}$ and triglycerides were lower in the malnourished group than in the non-malnourished group $(p=0.002$ and $p<0.001$, respectively) (Table 1 ).

\section{Clinical outcomes}

Mean duration of follow-up was $546 \pm 310$ days, with a maximum follow-up of 1092 days. Thirty-four patients (14\%) died after PCI, and the frequency of all-cause death was significantly higher in the malnourished group (31\%) than in the non-malnourished group (9\%; $p<0.001)$. MACCE occurred more frequently in the malnourished group (38\%) than in the non-malnourished group (11\%; $p<0.001$ ) (Table 2). Kaplan-Meier analysis showed a significantly lower survival rate after PCI in the malnourished group than in the non-malnourished group $(p<0.001)$ (Fig. 1). Cumulative incidence of MACCE including death was significantly higher in the malnourished group than in the non-malnourished group $(p<0.001)$ (Fig. 2).

\section{Associations of baseline systemic factors with MACCE}

Cox proportional hazards regression analysis was performed to investigate associations between baseline characteristics including malnutrition and MACCE. In univariate analysis, age, BMI (HR 0.91; 95\% CI 0.84-0.98; $p=0.016$ ), malnutrition (HR $3.69 ; 95 \% \mathrm{CI}$ 2.11-6.42; $p<0.001$ ), hemodialysis (HR 2.63; 95\% CI $1.51-4.58 ; p<0.001)$, prior heart failure, cholinesterase, hs-CRP, albumin (HR 0.43; 95\% CI 0.28-0.65; $p<0.001)$, eGFR, and LVEF were significantly associated with MACCE (Table 3). BMI and albumin were used to calculate GNRI. The eGFR was synonymous with hemodialysis, and the $95 \%$ CIs of cholinesterase and LVEF included 1.00. These factors were therefore 
Table 1 Baseline characteristics of study patients according to nutritional status

\begin{tabular}{|c|c|c|c|c|}
\hline Variables & $\begin{array}{l}\text { Overall } \\
(n=241)\end{array}$ & $\begin{array}{l}\text { Malnourished group } \\
(\mathrm{n}=55)\end{array}$ & $\begin{array}{l}\text { Non-malnourished group } \\
(n=186)\end{array}$ & $p$ value \\
\hline Age, years & $70 \pm 11$ & $77 \pm 9$ & $67 \pm 11$ & $<0.001$ \\
\hline Sex, male, n (\%) & $163(68)$ & $29(53)$ & $134(72)$ & 0.009 \\
\hline $\mathrm{BMI}, \mathrm{kg} / \mathrm{m}^{2}$ & $23.1[21.2,25.5]$ & $20.1[18.5,21.5]$ & $24.5[22.3,26.4]$ & $<0.001$ \\
\hline \multicolumn{5}{|l|}{ Risk factors, n (\%) } \\
\hline Hypertension & $191(79)$ & $44(80)$ & $147(79)$ & 1.00 \\
\hline Diabetes mellitus & $149(61)$ & $38(69)$ & $111(60)$ & 0.27 \\
\hline Dyslipidemia & $164(68)$ & $26(47)$ & $138(74)$ & $<0.001$ \\
\hline Current smoking & $45(19)$ & $7(13)$ & $38(20)$ & 0.24 \\
\hline Hemodialysis & $66(27)$ & $23(42)$ & $43(23)$ & 0.009 \\
\hline Prior myocardial infarction & $21(9)$ & $8(15)$ & $13(7)$ & 0.101 \\
\hline Prior stroke & $15(6)$ & $2(4)$ & $13(7)$ & 0.53 \\
\hline Prior heart failure & $20(8)$ & $7(13)$ & $13(7)$ & 0.18 \\
\hline \multicolumn{5}{|l|}{ Medication, n (\%) } \\
\hline Calcium-channel blocker & $120(50)$ & $27(49)$ & $93(50)$ & 1.00 \\
\hline ACEl & $19(8)$ & $4(7)$ & $15(8)$ & 1.00 \\
\hline ARB & $79(33)$ & $14(25)$ & $65(35)$ & 0.25 \\
\hline$\beta$-blocker & $48(20)$ & $10(18)$ & $38(20)$ & 0.85 \\
\hline Statin & $112(46)$ & $18(33)$ & $94(51)$ & 0.022 \\
\hline Proton pump inhibitor & $50(21)$ & $12(22)$ & $38(20)$ & 0.85 \\
\hline \multicolumn{5}{|l|}{ Laboratory data } \\
\hline Cholinesterase, U/L & $268[208,335]$ & $194[148,253]$ & $284[236,351]$ & $<0.001$ \\
\hline $\mathrm{hs}-\mathrm{CRP}, \mathrm{mg} / \mathrm{dL}$ & $0.26[0.09,1.23]$ & $3.1[0.36,8.26]$ & $0.19[0.08,0.58]$ & $<0.001$ \\
\hline $\mathrm{T}-\mathrm{CHO}, \mathrm{mg} / \mathrm{dL}$ & $164[140,197]$ & $155[131,171]$ & $172[142,203]$ & 0.002 \\
\hline LDL-C, mg/dL & $90[71,117]$ & $86[71,112]$ & $92[71,120]$ & 0.22 \\
\hline $\mathrm{HDL}-\mathrm{C}, \mathrm{mg} / \mathrm{dL}$ & $46[39,58]$ & $43[35,58]$ & $46[40,57]$ & 0.121 \\
\hline Triglyceride, mg/dL & $107[78,155]$ & $89[64,127]$ & $114[86,159]$ & $<0.001$ \\
\hline Albumin, $\mathrm{g} / \mathrm{dL}$ & $3.9[3.4,4.2]$ & $3.0[2.7,3.4]$ & $4.0[3.7,4.3]$ & $<0.001$ \\
\hline Uric acid, mg/dL & $5.5[4.2,6.7]$ & $5.6[3.8,6.7]$ & $5.4[4.3,6.7]$ & 0.61 \\
\hline $\mathrm{FPG}, \mathrm{mg} / \mathrm{dL}$ & $121[98,153]$ & $120[99,163]$ & $121[98,151]$ & 0.99 \\
\hline $\mathrm{eGFR}, \mathrm{mL} / \mathrm{min} / 1.73 \mathrm{~m}^{2}$ & $47.9[11.3,65.6]$ & $19.2[9.5,54.7]$ & $51.4[20.0,70.7]$ & 0.004 \\
\hline LVEF, \% & $55.0[41.4,66.2]$ & $49.4[38.8,64.9]$ & $56.8[45.8,67.2]$ & 0.030 \\
\hline
\end{tabular}

Values are shown as mean \pm standard deviation or median with interquartile range

$A C E I$ angiotensin-converting enzyme inhibitor, $A R B$ angiotensin II receptor blocker, $B M I$ body mass index, eGFR estimated glomerular filtration rate, $F P G$ fasting plasma glucose, $H D L$ - $C$ high-density lipoprotein cholesterol, $h s-C R P$ high-sensitivity C-reactive protein, $L V E F$ left ventricular ejection fraction, $L D L-C$ low-density lipoprotein cholesterol, $\mathrm{T}$-CHO total cholesterol

Table 2 Long-term clinical outcome

\begin{tabular}{lclll}
\hline & Overall & $\begin{array}{l}\text { Malnourished } \\
\text { group }\end{array}$ & $\begin{array}{l}\text { Non- } \\
\text { malnourished } \\
\text { group } \\
(\mathbf{n}=\mathbf{1 8 6})\end{array}$ & $\boldsymbol{p}$ value \\
& $(\mathbf{n}=\mathbf{2 4 1})$ & $(\mathbf{n}=\mathbf{5 5})$ & $21(11)$ & $<0.001$ \\
\hline MACCE & $42(17)$ & $21(38)$ & $17(9)$ & $<0.001$ \\
$\begin{array}{l}\text { Death } \\
\text { Non-fatal }\end{array}$ & $34(14)$ & $17(31)$ & $2(1)$ & 0.99 \\
$\begin{array}{l}\text { myocardial } \\
\text { infarction }\end{array}$ & $2(1)$ & $0(0)$ & & \\
Ischemic stroke & $6(2)$ & $4(7)$ & $2(1)$ & 0.025
\end{tabular}

Values are $\mathrm{n}(\%)$

MACCE major cardiovascular and cerebrovascular events not incorporated into the multivariate analysis. Multivariate analysis showed malnutrition (HR 2.30; 95\% CI 1.13-4.67; $p=0.020$ ) and hemodialysis (HR 2.17; 95\% CI 1.19-3.93; $p=0.011$ ) correlated positively with MACCE (Table 3). Furthermore, Cox proportional hazards models using malnutrition and hemodialysis revealed that patients with both malnutrition and hemodialysis showed greater risk of MACCE after PCI as compared to patients with neither malnutrition nor hemodialysis (HR 6.91; 95\% CI 3.29-14.54; $p<0.001$ ) (Fig. 3). A comparison of p-value for interaction of malnutrition and hemodialysis was $p=0.36$. 


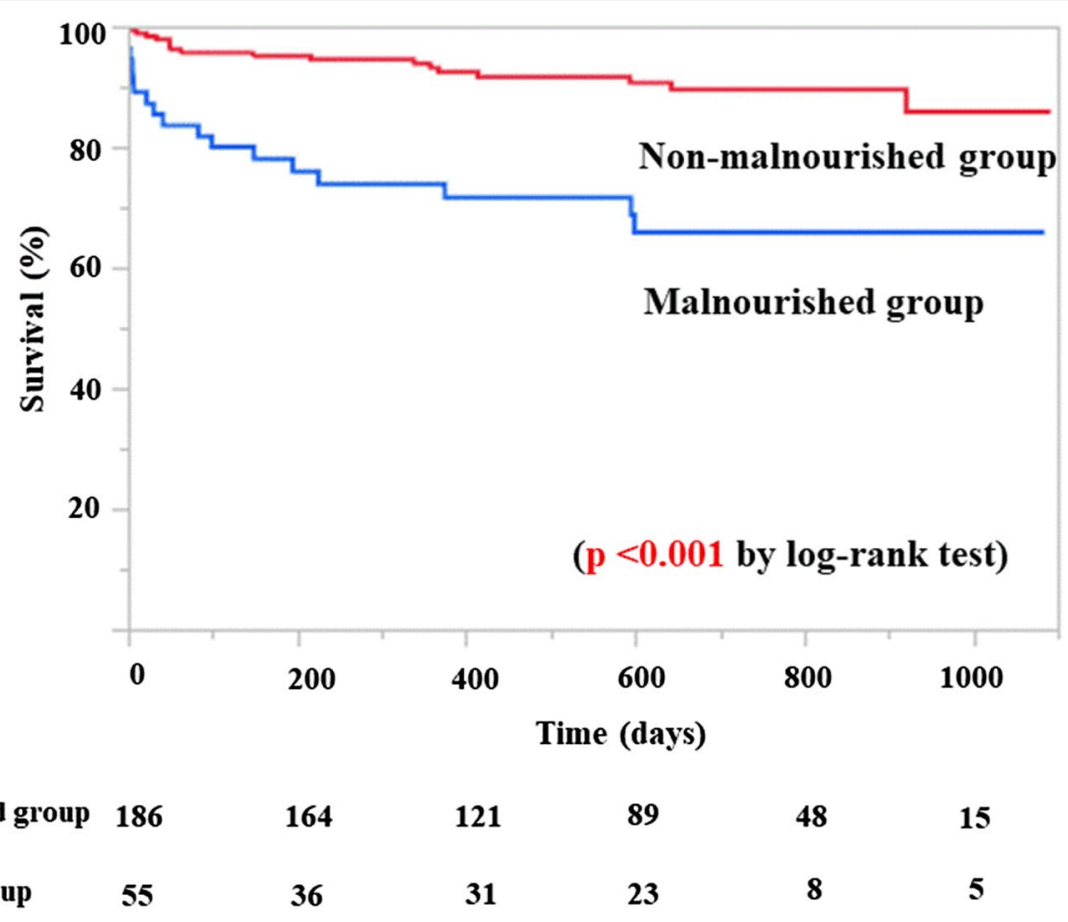

Fig. 1 Kaplan-Meier analysis of survival rate based on nutritional status

Number at risk

$\begin{array}{lccc}\text { Non-malnourished group } & 186 & 164 & 121 \\ \text { Malnourished group } & 55 & 36 & 31\end{array}$

23

5

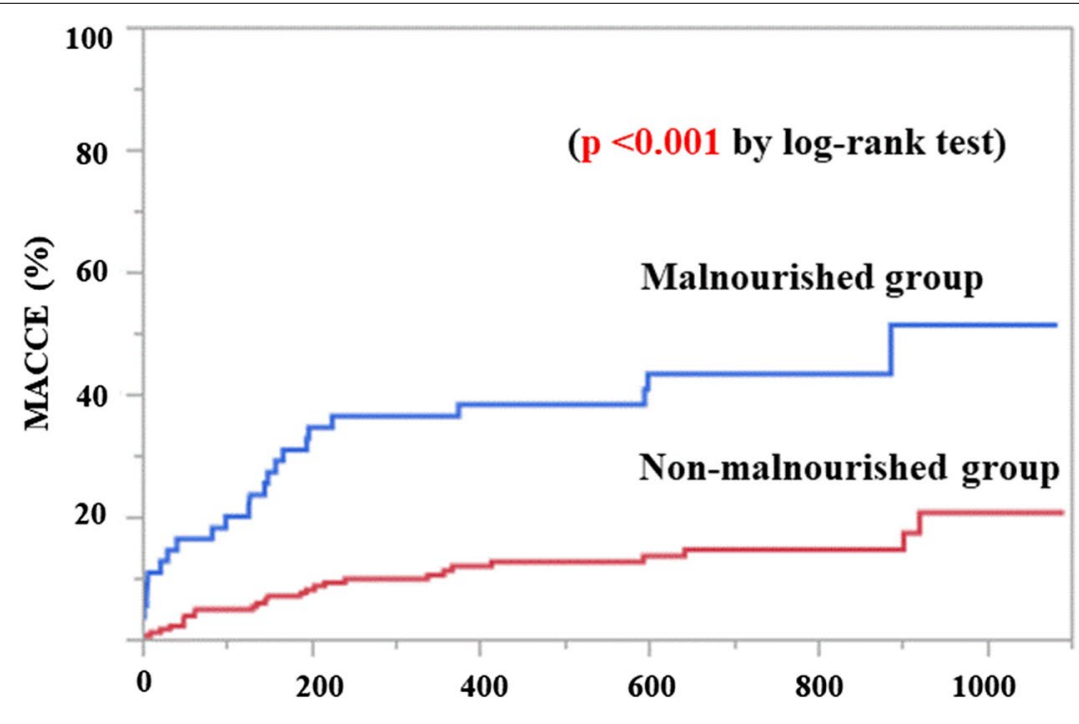

Number at risk

Time (days)

$\begin{array}{lcccccc}\text { Non-malnourished group } & 186 & 164 & 121 & 89 & 48 & 15 \\ \text { Malnourished group } & 55 & 36 & 31 & 23 & 8 & 5\end{array}$

Fig. 2 Cumulative incidences of MACCE based on nutritional status. MACCE major cardiovascular and cerebrovascular events

\section{Discussion}

In this retrospective cohort study of stable CAD patients with myocardial damage, we showed that: (1) patients with malnutrition displayed a higher incidence of MACCE as compared to patients without malnutrition; (2) malnutrition and hemodialysis were independent risk 
Table 3 Cox proportional hazards regression analysis for MACCE

\begin{tabular}{|c|c|c|c|c|c|c|}
\hline & \multicolumn{3}{|c|}{ Univariate analysis } & \multicolumn{3}{|c|}{ Multivariate analysis } \\
\hline & HR & $(95 \% \mathrm{Cl})$ & $p$ Value & HR & $(95 \% \mathrm{Cl})$ & $p$ Value \\
\hline Age & 1.04 & $(1.04-1.07)$ & 0.004 & 1.03 & $(0.99-1.06)$ & 0.092 \\
\hline Sex: male & 1.11 & $(0.62-2.36)$ & 0.58 & & & \\
\hline $\mathrm{BMI}$ & 0.91 & $(0.84-0.98)$ & 0.016 & & & \\
\hline Malnutrition $(\mathrm{GNRI}<92)$ & 3.69 & $(2.11-6.42)$ & $<0.001$ & 2.30 & $(1.13-4.67)$ & 0.020 \\
\hline Hypertension & 1.21 & $(0.62-3.84)$ & 0.34 & & & \\
\hline Diabetes mellitus & 1.01 & $(0.59-1.78)$ & 0.98 & & & \\
\hline Dyslipidemia & 1.48 & $(0.84-2.61)$ & 0.174 & & & \\
\hline Current smoking & 1.42 & $(0.41-4.88)$ & 0.57 & & & \\
\hline Hemodialysis & 2.63 & $(1.51-4.58)$ & $<0.001$ & 2.17 & $(1.19-3.93)$ & 0.011 \\
\hline Prior myocardial infarction & 1.64 & $(0.73-3.64)$ & 0.22 & & & \\
\hline Prior stroke & 3.16 & $(0.43-22.9)$ & 0.26 & & & \\
\hline Prior heart failure & 2.35 & $(1.10-5.01)$ & 0.027 & 1.73 & $(0.78-3.85)$ & 0.178 \\
\hline Calcium-channel blocker & 1.03 & $(0.59-1.80)$ & 0.91 & & & \\
\hline ACEI & 0.67 & $(0.21-2.18)$ & 0.52 & & & \\
\hline ARB & 0.90 & $(0.63-1.30)$ & 0.60 & & & \\
\hline$\beta$-blocker & 0.82 & $(0.39-1.69)$ & 0.59 & & & \\
\hline Statin & 0.68 & $(0.38-1.20)$ & 0.186 & & & \\
\hline Proton pump inhibitor & 1.15 & $(0.59-2.25)$ & 0.67 & & & \\
\hline Cholinesterase & 0.99 & $(0.98-1.00)$ & $<0.001$ & & & \\
\hline hs-CRP & 1.08 & $(1.03-1.11)$ & $<0.001$ & 1.01 & $(0.99-1.06)$ & 0.52 \\
\hline $\mathrm{T}-\mathrm{CHO}$ & 1.00 & $(0.98-1.00)$ & 0.056 & & & \\
\hline LDL-C & 0.99 & $(0.97-1.01)$ & 0.161 & & & \\
\hline HDL-C & 0.98 & $(0.97-1.00)$ & 0.28 & & & \\
\hline Triglycerides & 0.99 & $(0.98-1.00)$ & 0.073 & & & \\
\hline Albumin & 0.43 & $(0.28-0.65)$ & $<0.001$ & & & \\
\hline Uric acid & 1.01 & $(0.91-1.05)$ & 0.83 & & & \\
\hline FPG & 1.00 & $(0.99-1.00)$ & 0.61 & & & \\
\hline eGFR & 0.98 & $(0.97-0.99)$ & $<0.001$ & & & \\
\hline LVEF & 0.97 & $(0.96-1.00)$ & 0.010 & & & \\
\hline
\end{tabular}

$\mathrm{Cl}$ confidence interval, $\mathrm{HR}$ hazard ratio. Other abbreviations are as in Tables 1 and 2

factors for MACCE in stable CAD patients with myocardial damage; and (3) patients with both malnutrition and hemodialysis were associated with an additive increase in the risk of MACCE.

Nutritional status is an important factor that affects the prognosis of various diseases [15, 16]. As a tool of assessment for nutritional status, serum albumin level and BMI are often used in routine clinical practice. However, both are influenced by various non-nutritional factors, including inflammation, fluid status, and liver and renal functions [17-19]. BMI or albumin alone may thus be insufficient for assessing nutritional status. GNRI, as an index combining BMI and albumin [7], has recently been widely used in simple screenings of nutritional status and may be useful to overcome the shortcomings of individual indicators such as serum albumin and BMI. Recent studies have revealed that low GNRI is associated with worsened prognosis in patients with cardiovascular disease [8, 9, 20], and Kunimura et al. [21] demonstrated that low GNRI was independently associated with poor cardiac outcomes in patients with preserved ejection fraction after elective PCI for stable CAD. The present study demonstrated that malnutrition as assessed by GNRI represented an independent risk factor for MACCE in stable CAD patients with myocardial damage. Stable CAD patients with myocardial damage show poor prognosis compared to those without myocardial damage [10]. In addition, the ICELAND MI study demonstrated that patients with unrecognized myocardial infarction were at higher risk of all-cause mortality than patients without myocardial infarction. Furthermore, among patients with first myocardial infarction, previously unrecognized myocardial infarction was independently related to poor long-term clinical outcome, with 


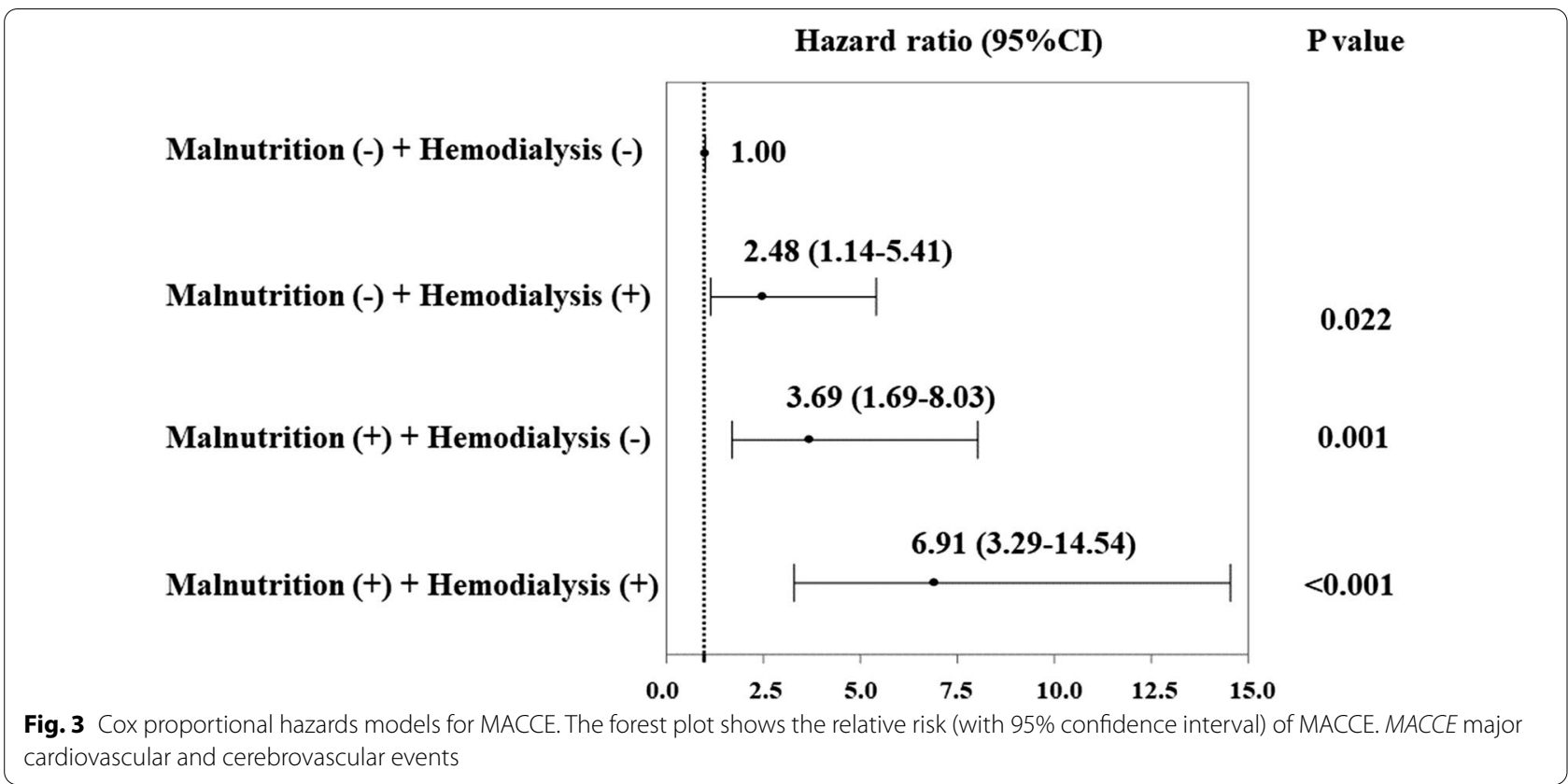

a more than threefold risk of mortality [22]. Intensive care is therefore needed to prevent recurrent cardiovascular events in CAD patients with myocardial damage compared to those without myocardial damage, and total management including prevention of energy and protein waste and feeding energy based on nutritional status may improve the prognosis for stable CAD patients with myocardial damage.

In the present study, hemodialysis was also independently associated with MACCE. Chronic kidney disease has been established as a risk factor for cardiovascular morbidity and mortality [23]. The ISCHEMIA-CKD trial showed stable CAD patients with advanced kidney disease including hemodialysis had high incidences of death and cardiovascular events compared to those without advanced kidney disease [24, 25]. Those previous reports may support the results of the present study. In patients with end-stage renal disease, malnutrition has been thought to have a close relationship with inflammation and atherosclerosis, and the concept of malnutrition-inflammation-atherosclerosis (MIA) syndrome has been suggested [26, 27]. MIA syndrome was then recognized to be an important clinical issue which should be addressed in patients with end-stage renal disease. Furthermore, previous studies have suggested that inflammation may deteriorate a generally catabolic state, leading to acceleration of protein degradation and suppression of protein synthesis in patients with endstage renal disease [28]. These mechanisms may cause protein-energy malnutrition [29]. Although nutritional status is affected by the interaction of multiple other factors, inflammation is recognized as a central factor in malnutrition. Chronic inflammation is known to lead to increase oxidative stress and the development of severe endothelial dysfunction, in turn leading to cardiovascular disease [27]. Indeed, we showed that patients with malnutrition and hemodialysis had additively elevated incidences of MACCE in this study. Statin therapy has not been found to achieve any obvious effect on prevention of cardiovascular events in patients with advanced kidney disease [30]. Hence, a novel strategy for preventing cardiovascular events may be needed in patients with advanced kidney disease. In recent years, some antiinflammatory therapies that do not affect lipid levels have demonstrated the ability to reduce cardiovascular events in CAD patients [31, 32]. Multidisciplinary care including nutritional management and the aforementioned antiinflammatory therapies may have the possibility of stopping the malignant cycle of MIA syndrome in patients with end-stage renal disease.

This study showed several limitations. First, the present retrospective study involved a relatively small cohort of patients. Second, although we assessed nutritional status using the GNRI as a combined index of BMI and albumin, we could not completely exclude systemic illnesses such as occult malignancies affecting BMI or albumin. In addition, the present study assessed the GNRI only on admission and did not assess changes in GNRI. Third, we were unable to evaluate another malnutrition index such as the Nutritional Risk Index, Mini Nutritional Assessment ShortForm scale or Maastricht Index, because the present 
study is retrospective, and we do not have the data those indexes need. Fourth, participants comprised 66 patients with hemodialysis (27\%) in this study, and it is reported that hemoglobin A1c may be underestimated in patients with hemodialysis. Thus, hemoglobin A1c was not included in the analysis. Fifth, the association of malnutrition with CAD or gender is an important issue to investigate; however, we were unable to address this association in the present study. Further clinical investigations are necessary to clarify this association.

\section{Conclusions}

The current study revealed malnutrition as assessed by GNRI offered an independent risk factor for MACCE among stable CAD patients with myocardial damage. Assessment of nutritional status may be helpful for stratifying the risk of cardiovascular events and encouraging improvements in nutritional status.

\section{Abbreviations}

ACEl: Angiotensin-converting enzyme inhibitor; ARB: Angiotensin II receptor blocker; BMI: Body mass index; CAD: Coronary artery disease; Cl: Confidence interval; eGFR: Estimated glomerular filtration rate; FPG: Fasting plasma glucose; GNRI: Geriatric nutritional risk index; HDL-C: High-density lipoprotein cholesterol; HR: Hazard ratio; hs-CRP: High-sensitivity C-reactive protein; IQR: Interquartile range; LVEF: Left ventricular ejection fraction; LDL-C: Low-density lipoprotein cholesterol; MACCE: Major cardiovascular and cerebrovascular events; MIA syndrome: Malnutrition-inflammation-atherosclerosis syndrome; PCl: Percutaneous coronary intervention; T-CHO: Total cholesterol.
\end{abstract}

\section{Acknowledgements}

We thank the staff of the Department of Cardiovascular Medicine and Hypertension at the Graduate School of Medical and Dental Sciences, Kagoshima University for their assistance with data processing.

\section{Authors' contributions}

RA, DK, TS, and KA performed coronary intervention; RA, DK, and AT analyzed the data; RA wrote the manuscript; DK revised the manuscript; and YI and MO drafted the work. All authors have read and approved the manuscript.

\section{Funding}

This work was supported in part by the Japan Society for the Promotion of Science KAKENHI (Grant No. 16H070890).

\section{Availability of data and materials}

The datasets used and/or analyzed during the current study are available from the corresponding author on reasonable request.

\section{Declarations}

\section{Ethics approval and consent to participate}

This study was approved by the Research and Ethics Committee of Kagoshima University Hospital and was carried out in accordance with the ethical principles stated in the 1975 Declaration of Helsinki. All patients provided written informed consent.

\section{Consent for publication}

Not applicable.

\section{Competing interests}

The authors declare that they have no competing interests.
Received: 31 May 2021 Accepted: 30 September 2021

Published online: 06 October 2021

\section{References}

1. Moran AE, Forouzanfar MH, Roth GA, Mensah GA, Ezzati M, Flaxman A, et al. The global burden of ischemic heart disease in 1990 and 2010: the Global Burden of Disease 2010 study. Circulation. 2014;129(14):1493-501.

2. Menees DS, Peterson ED, Wang Y, Curtis JP, Messenger JC, Rumsfeld JS, et al. Door-to-balloon time and mortality among patients undergoing primary PCI. N Engl J Med. 2013;369(10):901-9.

3. Lawler PR, Akinkuolie AO, Harada P, Glynn RJ, Chasman DI, Ridker PM, et al. Residual risk of atherosclerotic cardiovascular events in relation to reductions in very-low-density lipoproteins. J Am Heart Assoc. 2017;6(12):e007402. https://doi.org/10.1161/JAHA.117.007402.

4. Hassan A, Dohi T, Miyauchi K, Ogita M, Kurano M, Ohkawa R, et al. Prognostic impact of homocysteine levels and homocysteine thiolactonase activity on long-term clinical outcomes in patients undergoing percutaneous coronary intervention. J Cardiol. 2017;69(6):830-5.

5. Zheng HL, Lu J, Li P, Xie JW, Wang JB, Lin JX, et al. Effects of preoperative malnutrition on short- and long-term outcomes of patients with gastric cancer: can we do better? Ann Surg Oncol. 2017;24(11):3376-85.

6. Kobayashi I, Ishimura E, Kato Y, Okuno S, Yamamoto T, Yamakawa T, et al. Geriatric nutritional risk index, a simplified nutritional screening index, is a significant predictor of mortality in chronic dialysis patients. Nephrol Dial Transplant. 2010;25(10):3361-5.

7. Bouillanne O, Morineau G, Dupont C, Coulombel I, Vincent JP, Nicolis I, et al. Geriatric nutritional risk index: a new index for evaluating at-risk elderly medical patients. Am J Clin Nutr. 2005;82(4):777-83.

8. Honda Y, Nagai T, Iwakami N, Sugano Y, Honda S, Okada A, et al. Risk of cardiovascular disease morbidity and mortality in frail and pre-frail older adults: usefulness of Geriatric Nutritional Risk Index for assessing nutritional status and its prognostic impact in patients aged $\geq 65$ years with acute heart failure. Am J Cardiol. 2016;118(4):550-5.

9. Shiraki T, lida O, Takahara M, Masuda M, Okamoto S, Ishihara T, et al. The Geriatric Nutritional Risk Index is independently associated with prognosis in patients with critical limb ischemia following endovascular therapy. Eur J Vasc Endovasc Surg. 2016;52(2):218-24.

10. Marschner IC, Colquhoun D, Simes RJ, Glasziou P, Harris P, Singh BB, et al. Long-term risk stratification for survivors of acute coronary syndromes: results from the long-term intervention with pravastatin in ischemic disease (LIPID) Study. J Am Coll Cardiol. 2001;38(1):56-63.

11. Matsuo S, Imai E, Horio M, Yasuda Y, Tomita K, Nitta K, et al. Revised equations for estimated GFR from serum creatinine in Japan. Am J Kidney. 2009:53(6):982-92.

12. Guidelines for the management of obesity disease 2016. Japan society for the study of obesity: life science publishing; 2016.

13. Lang RM, Badano LP, Mor-Avi V, Afilano J, Armstrong A, Ernande L, et al. Recommendations for cardiac chamber quantification by echocardiography in adults: an update from the American Society of Echocardiography and the European Association of Cardiovascular Imaging. J Am Soc Echocardiogr. 2015;28(1):1-39.

14. The International Expert Committee. International Expert Committee Report on the role of the A1c assay in the diagnosis of diabetes. Diabetes Care. 2009;32:1327-33.

15. Norman $\mathrm{K}$, Pichard $\mathrm{C}$, Lochs $\mathrm{H}$, Pirlich M. Prognostic impact of diseaserelated malnutrition. Clin Nutr. 2008;27(1):5-15.

16. Nakagomi A, Kohashi K, Morisawa T, Kosugi M, Endoh I, Kusama Y, et al. Nutritional status is associated with inflammation and predicts a poor outcome in patients with chronic heart failure. J Atheroscler Thromb. 2016;23(6):713-27.

17. Horwich TB, Kalantar-Zadeh K, MacLellan RW, Fonarow GC. Albumin levels predict survival in patients with systolic heart failure. Am Heart J. 2008;155(5):883-9.

18. Kinugasa Y, Kato M, Sugihara S, Hirai M, Kotani K, Ishida K, et al. A simple risk score to predict in-hospital death of elderly patients with acute decompensated heart failure-hypo albuminemia as an additional prognostic factor. Circ J. 2009;73(12):2276-81. 
19. Liu M, Chan CP, Yan BP, Zhang Q, Lam YY, Li RJ, et al. Albumin levels predict survival in patients with heart failure and preserved ejection fraction. Eur J Heart Fail. 2012;14(1):39-44.

20. Minamisawa M, Miura T, Motoki H, Ueki Y, Nishimura H, Shimizu K, et al. Geriatric Nutritional Risk Index predicts cardiovascular events in patients at risk for heart failure. Circ J. 2018;82(6):1614-22.

21. Kunimura A, Ishii H, Uetani T, Aoki T, Harada K, Hirayama K, et al. Impact of Geriatric Nutritional Index on cardiovascular outcomes in patients with stable coronary disease. J Cardiol. 2017:69(1):383-8.

22. Amier RP, Smulders MW, van der Flier WM, Bekkers SC, Zweerink A, Allaart $\mathrm{CP}$, et al. Long-term prognostic implications of previous silent myocardial infarction in patients presenting with acute myocardial infarction. JACC Cardiovasc Imaging. 2018;11(12):1773-81.

23. Nagata M, Ninomiya T, Doi Y, Yonemoto K, Kubo M, Hata J, et al. Trends in the prevalence of chronic kidney disease and its risk factors in a general Japanese population: the Hisayama Study. Nephrol Dial Transplant. 2010;25(8):2557-64.

24. Bangalore S, Maron DJ, O'Brien SM, Fleg JL, Kretov El, Briguori C, et al. Management of coronary disease in patients with advanced kidney disease. N Engl J Med. 2020;382(17):1608-18.

25. Maron DJ, Hochman JS, Reynolds HR, Bangalore S, Obrien SM, Boden WE, et al. Initial invasive or conservative strategy for stable coronary disease. N Engl J Med. 2020;382(15):1395-407.

26. Stenvinkel P, Heimburger O, Paultre F, Diczfalusy U, Wang T, Berglund L, et al. Strong association between malnutrition, inflammation, and atherosclerosis in chronic renal failure. Kidney Int. 1999;55(5):1899-911.
27. Stenvinkel P, Heimburger O, Lindholm B, Kaysen GA, Bergstrom J. Are there two types of malnutrition in chronic renal failure? Evidence for relationship between malnutrition, inflammation and atherosclerosis (MIA syndrome). Nephrol Dial Transplant. 2000;15(7):953-60.

28. Kaysen GA. Malnutrition and the acute-phase reaction in dialysis patients-how to measure and how to distinguish. Nephrol Dial Transplant. 2000;15(10):1521-4.

29. Zha Y, Qian Q. Protein nutrition and malnutrition in CKD and ESRD. Nutrients. 2017;9(3):208. https://doi.org/10.3390/nu9030208.

30. Cholesterol Treatment Trialists (CTT) Collaboration. Impact of renal function on the effects of LDL cholesterol lowering with statin-based regimens: a meta-analysis of individual participant data from 28 randomised trials. Lancet Diabetes Endocrinol. 2016;4(10):829-39.

31. Ridker PM, Everett BM, Thuren T, MacFadyen JG, Chang WH, Ballantyne $C$, et al. Antiinflammatory therapy with canakinumab for atherosclerotic disease. N Engl J Med. 2017;377(12):1119-31.

32. Nidorf SM, Fiolet ATL, Mosterd A, Eikelboom JW, Schut A, Opstal TSJ, et al. Colchicine in patients with chronic coronary disease. N Engl J Med. 2020;383(19):1838-47.

\section{Publisher's Note}

Springer Nature remains neutral with regard to jurisdictional claims in published maps and institutional affiliations.
Ready to submit your research? Choose BMC and benefit from:

- fast, convenient online submission

- thorough peer review by experienced researchers in your field

- rapid publication on acceptance

- support for research data, including large and complex data types

- gold Open Access which fosters wider collaboration and increased citations

- maximum visibility for your research: over 100M website views per year

At BMC, research is always in progress.

Learn more biomedcentral.com/submissions 